\title{
Editorial
}

\section{La noción de medio en Sergio Roncallo-Dow y la mediación de la pérdida}

\section{Edward Goyeneche-Gómez}

DOI: 10.5294/pacla.2020.23.s.1

Para citar este editoral / to reference this editorial / para citar este editorial Goyeneche-Gómez, E. (2020). La noción de medio en Sergio Roncallo-Dow y la mediación de la pérdida. Palabra Clave, 23(supl.), e23s1. https://doi.org/10.5294/ pacla.2020.23.s.1

What do you want? What do you want?

I want rock'n'roll, yes I do Long live rock'n'roll

Def Leppard

\section{Sergio Roncallo-Dow en su estudio. Edward Goyeneche-Gómez, 11 de julio de 2018.}

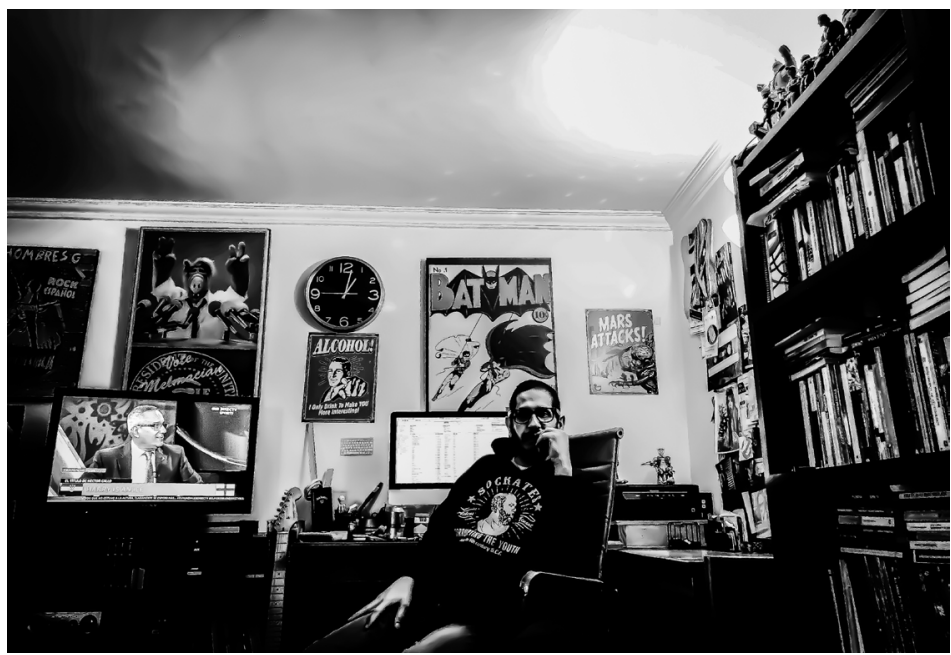

Fuente: archivo personal.

1 https://orcid.org/0000-0003-0746-4310. Universidad de La Sabana, Colombia. edward.goyeneche@unisabana.edu.co 
En el ahora buscamos a Sergio Roncallo-Dow con la mediación de la pérdida. Su no presencia delata nuestra batalla por re-encontrarlo tal como él era. Lo perseguimos en su obra, en sus palabras, en sus composiciones, en sus fraseos, porque sabemos que él está allí. Igual que en el nombre del noema de la fotografía, que encuentra Roland Barthes en la imagen de la infancia de su madre (1989, p. 121), en los textos de Sergio percibimos el "Esto ha sido", a pesar de no ser imagen fotográfica. Porque en el lenguaje, escrito, también podemos encontrar iconicidad e, incluso, indicialidad en la propia vivencia de la significación textual, formal, siguiendo a Wittgenstein (1999). Y, en últimas, en todo caso, como nos lo ha enseñado el propio Barthes, en el propio ejercicio de interpretación de la obra de Sergio, podemos estar construyendo un mito de él mismo en este uso metalingüístico de sus palabras (2002, p. 206).

En su obra, también está su presencia, forma, presentada en el presente, en el ahora. De ahí que en este número suplemento de la Revista Palabra Clave, su revista —uno de sus tantos yos-, Sergio permanece, más que nunca, en esta comunidad académica venciendo el tiempo y habitando nuestro mundo. Las palabras de sus amigos y colegas, aquí contenidas, son nuestro sincero y humilde homenaje. La mediación de la pérdida nos lleva a pensar en el re-conocimiento de la obra de Sergio como lectores, como receptores, como quien se apropia desde el uso, siguiendo la expresión del maestro de Sergio, Jesús Martín-Barbero (1997, p. 10).

Pero aquí vamos a invertir la fórmula. Vamos a ir de las mediaciones a los medios. Porque la noción de medio en Sergio nunca excluyó la mediación: no separó la técnica y la cultura. Cuando escribimos Volver a los clásicos: teorías de la comunicación y cultura pop (Roncallo-Dow, Uribe-Jongbloed y Goyeneche-Gómez, 2016), partimos para el análisis de los medios de comunicación de la noción de ecología mediática que planteó, como lo resume Lum, estudiar la relación simbiótica entre las personas y las tecnologías mediáticas que crea y usa: "es 'el estudio de los medios de comunicación pensados como entornos' [...] y de la manera compleja en que estos sistemas de comunicación impactan la forma en que la gente piensa, siente y se comporta" (2014, p. 137). La repetida expresión de Marshall McLu- 
han el medio es el mensaje se convirtió para nuestro análisis mediático de la cultura pop en un mantra para releer las teorías clásicas desde una visión ampliada de la propia noción de comunicación. Y el aporte fundamental de Sergio estaba, justamente, en su capacidad para abrir el propio campo del conocimiento amarrado a ideas fijas, limitadas o encasilladas.

Hace un tiempo comenzamos a pensar en hacer una versión extendida de Volver a los clásicos, para incluir reflexiones y análisis sobre otras teorías clásicas desarrolladas a partir de la década de los sesenta hasta nuestra época. Yo decidí abordar la escuela de Palo Alto y Sergio me trazó el camino de la posible línea argumentativa, que, luego, se convirtió, más bien, en una guía interpretativa sobre sus propias reflexiones. En los intercambios recientes, muchos de ellos por chat o por teléfono, dada la condición de salud de Sergio, me daba las pistas de una lógica sencilla que permitía entender la importancia de los procesos de construcción del sentido y de la producción de la significación en los entramados de relaciones sociales y humanas.

Hay que arrancar con Aristóteles en los Tópicos, me dijo, y yo comencé a ponerme nervioso. En la propia noción de dialéctica está el punto de partida, porque, de entrada, identificaba la presencia de interlocutores que intercambian preguntas y respuestas en torno a un tema en un juego reglado que se constituye en un diálogo, me señaló. Y su aguda observación no buscaba poner una barrera desde su erudición como filósofo a mi rígida lógica sociológica que para nada hubiese incluido a Aristóteles en la bibliografía. Pero es que desde los griegos queda claro que en la vida cotidiana siempre estamos interactuando, hablando, discutiendo, persuadiendo (Roncallo-Dow, 2009b). Yo le señalé que, visto así, parecía recaer sobre esa reflexión una visión esencialista sobre la propia comunicación y sobre lo que es lo propiamente humano. Puede ser, me dijo, pero recuerda que lo humano comenzó propiamente con el lenguaje, con el dar sentido, me enfatizó.

Si quieres entender la idea de interacción piensa en Ser y tiempo de Martin Heidegger (2006), continuó. No, no, no, le respondí. Imposible. $\mathrm{Ni}$ loco voy a saltar de Aristóteles a Heidegger. Y comenzó a explicarme. El hombre es el Dasein, el ser-en-el-mundo. Es un ente intramundano que 
siempre se encuentra volcado hacia el mundo, teniendo que ver con él: de algún modo, interactuando. El hombre es en tanto es-en-el-mundo y este mundo es su plexo referencial. Desde esta perspectiva de la mundanidad, la interacción con el mundo, el tener que ver con algo, el andar siempre en alguna situación, ser no es otra cosa que ser-en-el-mundo. Sergio lo escribió en 2008:

La idea básica es que, como diría Heidegger a propósito del hombre, el ser-ahí (Dasein) es siempre Mitdasein. "El mundo del Dasein es un mundo en común (Mitwelt). El ser-en es un ser-con-otros. El ser-ensí intramundano de estos es la coexistencia (Mitdasein)" [...]. Esto implica pensar la existencia como coexistencia: ser es ser-con, sercon-el-otro. Si al hablar de los útiles, Heidegger habla del Ser como un estar a la mano, al hablar de los existentes humanos, se habla del acompañar. El otro que me acompaña, precisamente desde el sercon. Es por esto que el mundo del Dasein es un mundo del "con", ser es ser-con-otros. (Roncallo-Dow, 2008, p. 99)

La noción de otredad respecto del problema de la interacción humana no me resultaba para nada novedosa, dado que estaba en el propio origen de la sociología moderna. De hecho, Norbert Elias señaló, refiriéndose a la definición de la propia materia, que el principio básico resultaba casi trivial: "entenderse a sí mismo como una persona entre otras" (1982, p. 16).Y los propios sociólogos norteamericanos, precursores de Palo Alto, habían apuntado desde muy temprano en el siglo XX a marcar como eje central en la investigación sociológica la idea de la relación y no oposición entre el individuo y la sociedad: el "sí mismo" no es el individuo que se aísla del mundo, de la sociedad, sino un lugar-tiempo de comunicación, de fusión, entre individuo y sociedad (Berger, 2012).

Pero Sergio pretendía llevarme más allá. La pregunta no era solo reconocer el carácter social de la comunicación como una manera, casi natural e instintiva, de relacionarnos, sino analizar cómo ocurre el propio acto comunicativo en la propia interacción. Para ello, me formuló una pregunta aparentemente muy simple: " $i$ Es el acto comunicativo un acto reglado?”. La respuesta parecía resultar obvia. Por supuesto que sí, le dije, toda trama de significación, de sentido, tiene límites, normas, reglas, códigos. La discusión, sin embargo, debía marcar algunos puntos de partida. Watzlawick 
(2014), y sus colegas de Palo Alto, habían instituido la repetida idea de la imposibilidad de la no comunicación: "no es posible no comunicar". En ese sentido, parecía evidente que la proposición del autor sobre la imposibilidad de no comunicar partía de la definición de comunicación como una unidad de conducta: "toda conducta es comunicación" (p. 15).

Tenía sentido, en esa línea argumentativa, pensar que si ser-en-el-mundo es un ser-con-otros, de Heidegger a Roncallo, la propia noción de conducta de Watzlawick se conectaba con la noción de acción social de Weber que se centraba en el problema de la conducta humana y la otredad: "La 'acción social', por tanto, es una acción en donde el sentido mentado por un sujeto o sujetos está referido a la conducta de otros, orientándose por esta en su desarrollo" (Weber, 1964, p. 5). Para Watzlawick, entonces, "no hay no conducta” porque es imposible no comportarse en una interacción social: "Ahora bien, si se acepta que toda conducta en una situación e interacción tiene un valor de mensaje, es decir, es comunicación, se deduce que por mucho que uno lo intente, no puede dejar de comunicar" (p. 16).

Pero, justamente, con Sergio, el problema que marcábamos, en esa idea de comunicación, tenía que ver con el problema de las reglas, los controles y las regulaciones de esas conductas. El propio Watzlawick reconocía que, cuando pensamos o experimentamos los aspectos relacionales de la comunicación (lo conativo), estamos participando de un proceso metacomunicacional, es decir, del uso de códigos que están reglados, que son no conscientes y que pre-existen a los propios sujetos de conducta: "La capacidad para metacomunicarse de forma adecuada constituye no solo una condición sine qua non de la comunicación eficaz, sino que también está íntimamente vinculada al complejo problema concerniente a la percepción del selfy del otro (2014, p. 21).

Sergio reconocía en esta discusión que la interacción suponía un rol activo tanto del emisor como del receptor y, en esa medida, entraban en escena las reglas, como una especie de mediadores de la interacción. Siguiendo a Watzlawick, se podía señalar que al estar en un permanente comportarse resultaba particularmente útil adscribirse a la gramática de los comporta- 
mientos y seguir las reglas: de ahí la idea de una comunicación eficaz. Sergio me diría que la comunicación se convierte en el marco de toda actividad humana y en esa medida el mapa de navegación resulta indispensable. La manera como me estoy comunicando con él, usando muchas de sus propias palabras, se constituye en sí mismo en un acto metacomunicacional - en una conducta - codificado por el propio lenguaje que utilizaba Sergio para comunicarse conmigo, mientras discutíamos este problema, y para comunicarse con el mundo por medio de sus textos. Sergio reconocía, asimismo, que su propio lenguaje era parte de una puesta en escena simbólica, en este teatro académico, que incluía un proceso interpretativo específico.

En ese sentido, el propio concepto de interaccionismo simbólico de Erwin Goffman (2001), siguiendo con Palo Alto, avanzaría fuertemente sobre el análisis de esos procesos de codificación de las conductas y de la comunicación humana. Goffman analiza las formas como el individuo se presenta en sus actividades cotidianas ante otros, los modos como los individuos guían y controlan las impresiones que quieren dar ante los demás y el tipo de cosas que un individuo puede o no hacer mientras actúa en un escenario social determinado: la relación entre el yo, el mí (self) y el otro. En principio, el análisis está centrado en la forma como los actores sociales definen la situación en la interacción social. Se trata de un proceso de recolección de información que les permite a los actores de la interacción saber lo que se espera de ellos en un cuadro normativo determinado y generar marcos de referencia que les permita comunicarse con eficacia y verosimilitud en un juego social; un juego de lenguaje, diría Sergio siguiendo a Wittgenstein (1999), que tiene reglas en su uso.

Ves, me diría Sergio, rápidamente estamos de vuelta al lenguaje. Pero no al lenguaje como cosa aislada o reducida a un contenido. Diríamos, siguiendo a Watzlawick, el lenguaje es, igualmente, una unidad de conducta, un lugar de interacción con un otro. Los lenguajes, un lenguaje, el lenguaje es un medio técnico, una extensión del ser humano, es decir, un espacio, un ambiente, de transformación sensorial y de relacionamiento. Y allí mismo está el punto de partida de la idea de medio de Marshall McLuhan: "Así, un primer punto de partida tendría que ver con la posibilidad de pensar el 
medio más como un sistema de naturaleza, como un espacio físico-cultural en el que tienen lugar determinados acontecimientos y cambios" (Roncallo-Dow, 2009, p. 363). Sergio escribió:

McLuhan centró su atención en el modo como las mutaciones en la tecnología (de la comunicación, especialmente) producía cambios en los modos de habitar el mundo, de relacionarse consigo mismo y con Ios otros; analizó los cambios propios de la subjetividad del hombre del siglo XX y, abandonando una inicial posición coincidente con la Escuela de Frankfurt, poco a poco empieza a comprender la necesidad de entender la tecnología no como un dispositivo de alienación, sino como una extensión del cuerpo y de la mente. (2009a, p. 363)

Para W.J. T. Mitchell, McLuhan amplió la visión y la noción de medio: "Para McLuhan, todo, de la piel al vestido, al sistema de raíles, constituía el campo de la comunicación y la expresión, formando una 'segunda naturaleza' en torno a los individuos y las sociedades (Mitchell, 2019, p. 21). Resulta claro cómo nos recordaba Sergio constantemente, entonces, que "el contenido de cualquier medio es el usuario", lo cual aplica también a cualquier lenguaje. Así lo reafirmó Eric McLuhan:

Comentando, a propósito de algo que había escrito o dicho anteriormente, McLuhan (1967) ofreció estas palabras: "Ahora está perfectamente claro para mí que todos los medios son ambientes. Como ambientes, todos los medios tienen todos los efectos que los geógrafos y biólogos han asociado con los ambientes en el pasado. Los ambientes dan forma a sus ocupantes. Una persona, protestando sobre mi observación de que 'el medio es el mensaje', simplemente dijo: 'McLuhan quiere decir que el medio no tiene contenido'. Esta observación fue muy útil para mí porque puso de manifiesto lo obvio, a saber, que el contenido de cualquier medio es el usuario. Esto se aplica igualmente a la luz eléctrica, a cualquier lenguaje, y, por supuesto, a la vivienda, automóviles, e incluso herramientas de cualquier tipo. Es evidente que el usuario o el contenido de cualquier medio está totalmente ajustado al carácter de este ambiente hecho-por-el-hombre. Su entera vida sensorial organiza sus jerarquías y su dominancia de conformidad con el ambiente en el que opera. (2008, p. 27)

La noción de medio de McLuhan aparece entonces como un eje transversal a las reflexiones de Sergio sobre los medios, pero, al mismo tiempo, la noción de medio de McLuhan se ha expandido en la propia relectura de 
Sergio hacia líneas interpretativas mucho más diversas y abiertas, sobre todo en relación con sus reflexiones sobre la idea de lenguaje/s como medio. Sergio, por ejemplo, coincide con Mitchell en leer a McLuhan desde una visión que supera la perspectiva reduccionista de la comunicología y la integra a discusión de todos los ámbitos, sobre todo del arte. Para Mitchell como para Sergio, la noción de medio no debe ser totalizante:

Me gustaría matizar aún más la noción "medio en tanto que situación" o medio ambiente, sugiriendo que este nunca consiste en el todo de una situación. Una de las tentaciones más profundas del concepto de medios es su tendencia a la totalización. Incluso en el antiguo modelo de medios como dispositivo de comunicación llevaba incorporada esta tendencia. Como un acordeón, el modelo de emisor-medio-receptor (llamemos a esto la imagen "telefónica") se expande inmediatamente para incluir la función de emisor/receptor como componentes del medio. Enseguida todo es un medio, el antiguo mantra derrideano regresa para rondarnos, y no hay nada fuera de los medios de comunicación. Preferiría decir que siempre hay algo fuera del medio, a saber, la zona de inmediatez y de lo no mediado que cada medio produce y encara. $(2019$, p. 112)

El abordaje de la noción de medio de McLuhan, desde Sergio, resaltó, constantemente, el problema de la producción del significado en los procesos de transformación técnica y tecnológica, y el propio sentido que encuentra el sujeto en esos procesos al habitar el mundo. Asimismo, Sergio reconocía, permanentemente, la relación de los medios, igual que lo hace Mitchell, por ejemplo, con lo social:

Un medio, como dice Raymond Williams, es una "práctica social material", no una esencia especificable dictada por alguna materialidad elemental (pintura, piedra, metal) 0 por una determinada técnica 0 tecnología. Los materiales y las tecnologías intervienen en el medio, pero también lo hacen las habilidades, los hábitos, los espacios sociales, las instituciones y los mercados. (2019, pp. 124-125)

\section{Para Sergio:}

En primer lugar, lo que indica McLuhan tiene consecuencias fuertes en lo que llamaríamos la producción de significado, toda vez que, al desplazar el fulcro de la operatividad propia de cada órgano a los 
objetos técnicos que se constituyen es sus prolongaciones, hay un descentramiento en el modo mismo de empoderamiento del mundo. Una palanca 0 un ordenador se constituyen en unidades de producción de significación en la medida en que desvelan un mundo que estaba oculto y, consecuentemente, trasmutan la forma de vida precedente en una nueva. El movimiento constante que se da a partir de las prolongaciones va a dar como resultado una mutación en los juegos de lenguaje en los que el sujeto está inmerso. De ahí que cuando señalaba más arriba la plausibilidad de hablar de una cosmovisión mcluhaniana, lo que trataba de sugerir es que, tras cualquier prolongación de los sentidos, lo que tiene lugar es un cambio de fondo en la relación que existe entre el hombre y el mundo, pues, de algún modo, es por medio de los sentidos que el hombre toma contacto con su entorno, y el sentido que lo liga con su entorno modifica su conducta y su mentalidad. (Roncallo-Dow, 2011, p. 126)

Como lo señala Sergio, McLuhan trabaja un punto que es clave y que tiene que ver con la premisa de que el lenguaje constituye el artefacto humano muy sofisticado, y con el modo en el que este modela las formas de empoderamiento del mundo: "En otras palabras: el lenguaje es el artefacto más complejo, y a lo que asistimos a lo largo de la historia es a un movimiento de fragmentación que se objetiva en la concreción de técnicas cada vez más especializadas, pero que, a su vez, tienen consecuencias en el lenguaje mismo (Roncallo-Dow, 2011, p. 133).

Finalmente, en este sentido, Sergio, me insistiría, en esas reflexiones, a ratos dispersas y difíciles, que un buen ejemplo de cómo se podía complejizar el problema de la díada medio/lenguaje era el análisis que él, junto con su amigo Enrique Uribe-Jongbloed, había propuesto de la relación entre medio y mito, poniendo a dialogar a McLuhan y Barthes. Logan ya había hecho hincapié en esas interacciones entre ámbitos:

El estudio de los medios, el lenguaje y la tecnología y sus efectos revelaron la superposición de estas tres categorías. Los lenguajes y las tecnologías median y crean entornos como los medios. Los medios y los lenguajes son, ambos, técnicas y herramientas al igual que cualquier otra forma de tecnología. Los medios y las tecnologías son lenguajes de expresión que, como un lenguaje, comunican información con su propia semántica y sintaxis. Dadas estas superposiciones, afirmamos que el estudio ecológico de los medios no puede restrin- 
girse a medios de comunicación estrechamente definidos, sino que también debe incluir la tecnología y el lenguaje y las interacciones de estos tres dominios, que juntos forman un ecosistema de medios. (2010, p. 36)

En el análisis del videoclip que hicimos en Volver a los clásicos quedaba claro que este lenguaje-medio/medio-lenguaje podía definirse, siguiendo a Barthes, como un sistema de comunicación que en sí mismo se tornaba en un mito. Desde la idea primordial el mito es un habla, Barthes se propone elaborar lo que llama mito que constituye, en esencia, un modo de comprender la forma en la que se estructuran los juegos de lenguaje en un entramado social:

La noción barthesiana del mito resulta particularmente rica en este contexto no solo por las particulares cercanías que tiene con la forma en la que McLuhan lee la realidad, sino porque permite evidenciar, en el carácter productivo del lenguaje, las formas de darse de esa producción de significado y, consecuentemente, permite asir más fuertemente la idea del medio mcluhaniano, que nos ha venido guiando. (Roncallo-Dow et al., 2016, p. 60)

Para Sergio y Enrique, en conclusión:

El interés primario del canadiense pasa - en una buena parte - por el hecho de evidenciar la dis-locación sensorial que producen las complejizaciones del sistema técnico y la capacidad poiética de lo técnico en tanto capaz de afectar al hombre. Ahora bien, esa capacidad de afectar, propia de lo técnico, re-configura al hombre. Sin embargo, esa re-configuración no puede entenderse como un movimiento unidireccional, pues esto no solo entraría en contradicción con la idea de la relación transductiva entre hombre y técnica, sino que, además, nos llevaría por el sendero del determinismo. Así, al aproximarnos a Barthes, lo que se pretende es mirar la otra arista de la poiésis que se da en lo técnico y que tiene que ver con el modo mismo en que el mundo es leído y comprendido por el hombre, pues esta dimensión de la lectura del mundo acompaña las reflexiones de McLuhan. (Uribe-Jongbloed y Roncallo-Dow, 2013, p. 184)

"Pera, pera”, Goyeneche, me diría Sergio. "A este tema hay que seguirle trabajando. La propuesta era mandarte una sonda, pero esto requiere que te metas a fondo a estudiar. Mis amigos y colegas, con los que he trabaja- 
do estos temas largamente, pueden ayudarte a entender mejor estas ideas. Apóyate en ellos, en los otros", me diría el maestro. Por ello en este número suplemento de la Revista Palabra Clave, en este homenaje a Sergio, los ensayos escritos por sus amigos y colegas nos ayudan a entender mucho mejor la importancia y la dimensión de su obra, con una cercanía y conexión que son, sin duda, conmovedoras.

En el primer ensayo, "La cultura pop en el pensamiento de Sergio Roncallo Dow: el sur es el mensaje”, Enrique Uribe-Jongbloed, Daniel Aguilar-Rodríguez y Hernán D. Espinosa-Medina abordan la compleja noción de cultura popular en la obra de Sergio, desde las premisas fundamentales de la ecología de los medios, articulada con ideas clave sobre la nostalgia, que fueron pensadas por Sergio en sus reflexiones sobre el lenguaje televisivo, la telenovela, el videoclip o el rock, para entender la cultura pop "como aquella relación constante y negociación perpetua entre los medios y nuestra vida cotidiana”. En el texto Sergio es una metaimagen que permite entender cómo él se pensaba a sí mismo y se implicaba en sus propios objetos de análisis. Su propio estudio (su lugar en el mundo), como lo muestran los autores, era en sí mismo una experiencia nostálgica, conceptual y académica sobre su propia vida.

En "El mundo, espuma del tiempo en nuestra mano: chatear con Sergio (Roncallo-Dow)”, el segundo ensayo, Harvey Murcia Quiñones y Carlos Arango piensan la obra de Sergio, desde sus propias conversaciones e intercambios, muchos de ellos por chat, centrándose en el problema del comunicar como un encuentro con el otro para estar en el mundo, a partir del análisis complejo y riguroso de las nociones lenguaje, medio y tecno-logía: “Qué se comunica en el lenguaje?” es la pregunta central del capítulo de Benjamin; y la que se convierte en un eje primordial para comprender las tecnologías como enhebradoras del mundo. Lo que se comunica es el lenguaje a sí mismo, en sí mismo; es el mismo medium de la comunicación, pues todo se "comunica en el lenguaje, no por medio del lenguaje".

Los autores, conectando con Sergio en su propio lenguaje, muestran como él se convirtió en un analista de los cambios de su entorno, para en- 
tender las nuevas formas de producir sentido y habitar el mundo: "Hacer de la vida una obra de arte se tornaba en él como algo menos platónico para convertirse en una performance más en la línea de un posible Heidegger ft. Wittgenstein". Sergio re-significaba y se apropiaba de las ideas que estudiaba, pensaba, vivía: "En vez de limitarse a repetir estas tesis como frases (cerradas, unívocas, pre-definidas) en sus trabajos, homenajes a la morada heideggeriana, el aura benjaminiana, el mundo wittgensteiniano y la ecológica mcluhaniana, Sergio probó desde ellos una fraseología (una propia forma de hablar) mediante aperturas, vivisecciones, in-versiones, re-versiones y contra-venciones provocadoras".

En "La comunicación se genera en el diálogo de la cultura: reflexiones sobre el concepto de audiencia en el pensamiento de Roncallo-Dow", el tercer ensayo, Manuel Ignacio González Bernal, evocando sus experiencias personales del trabajo académico con Sergio, nos acerca a la noción de audiencia, fundamental para los estudios de comunicación, desde la mirada singular de Sergio que va de la filosofía platónica, pasando por una genealogía reflexiva sobre las concepciones y miradas sobre el problema, y llegando, siguiendo la línea argumentativa de González, a la construcción de una ontología del concepto basada en la relación entre el sujeto, el mensaje y el contexto cultural:

Sin embargo, hacerlo resulta de central importancia, pues un proceso de comunicación exitoso, más allá de entregar un mensaje, implica una decodificación, una significación y, por tanto, una transformación del sujeto receptor. Esta determinación de la persona tiene que ver con la posibilidad de cada sujeto de leer e interpretar creativamente las formas simbólicas, incluidos los productos mediáticos, y llevar el resultado a su vida cotidiana. En este sentido, se produce una doble determinación [...], pues el consumo mediático determina el acervo cultural de los sujetos consumidores y, a la vez, dicho acervo es la base para el ejercicio hermenéutico propio de la generación del sentido.

En "Zombis, alienígenas y rockeros: Sergio Roncallo-Dow en el espejo retrovisor", el cuarto ensayo, Carlos A. Scolari intenta re-leer y reconstruir de manera fragmentaria y no lineal, como un mosaico, la obra de Sergio homenajeando su propio enfoque y método. Para Scolari, Sergio sabía que 
todo lo que habita el mundo debía servir para pensar. Moviéndose entre el mundo "ortodoxo" y los márgenes, el outsider, como lo denomina Scolari, Sergio fue un gran académico pero también un editor notable, que logró posicionar la Revista Palabra Clave, dándole su toque personal. El cuestionario sobre los zombis que le hace a Scolari es maravilloso. Esa comunicación sencilla, fluida y que atrapa la complejidad en los asuntos más banales.

En "Pensamientos, recuerdos y conversaciones: un diálogo con Sergio Roncallo-Dow, pensador, filósofo y colega”, el quinto ensayo, María Catalina Cruz-González, Julián Penagos-Carreño y Juan David Cárdenas-Ruiz, cada uno desde su propia mirada de la relación académica y personal con Sergio, transitan por los nod os y las tramas que construyó Sergio en su habitus académico, sus prácticas, sus enseñanzas, su generosidad, a partir de su propia nostalgia que atraviesa el recuerdo y la reminiscencia como señales activas del presente.

Cruz-González describe a su mentor como alumna, como colega, como coautora, como asistente editorial, en el lugar del Jedi: su maestro Yoda. Penagos-Carreño lo recuerda en sus conversaciones sobre la relación entre la memoria, la técnica y la comunicación, y encuentra, incluso, ciertas bases fundamentales de su propia tesis de doctorado que obligaban a escudriñar la propia idea de la separación entre técnica y cultura, que McLuhan había resuelto desde el punto de vista de "el medio es el mensaje" y que Penagos-Carreño repensaba en la idea "el medio es la memoria". CárdenasRuiz revela cómo Sergio empieza a expandir sus intereses académicos al campo del análisis del conflicto y la paz en relación con los medios de comunicación para el caso colombiano, mostrando su claro interés en la política, en el encuentro con un nuevo lugar: el semillero de investigación. El positivismo y lo cuantitativo entró con Cárdenas-Ruiz y Cruz-González en el horizonte del trabajo de Sergio: "Metámosle el robot", diría el maestro.

En "Una vuelta breve a la participación política digital y el acontecimiento mediático en las ideas de Sergio Roncallo", el sexto ensayo, Ana María Córdoba-Hernández y José Manuel Robles-Morales evocan sus encuentros académicos con Sergio en torno a las transformaciones en los pro- 
cesos mediáticos generados dentro de los ambientes digitales y su relación con la participación política en las redes sociales; asimismo, muestran el interés de Sergio por las formas como en estos nuevos entornos se construye específicamente el acontecimiento mediático. Los autores sitúan la mirada de Sergio más allá de las visiones radicalmente apocalípticas o integradas en que los estudiosos de los fenómenos de comunicación suelen caer frecuentemente.

Finalmente, en el epílogo de este número suplemento de la Revista Palabra Clave, Andrew McLuhan cierra nuestro homenaje, con unas sentidas palabras sobre su encuentro y experiencia con Sergio durante su estancia en Colombia, para el lanzamiento del Doctorado en Comunicación de la Universidad de La Sabana el 18 de mayo de 2019, valorando la pasión, el coraje y la ferocidad de Sergio que él percibió durante ese tiempo compartido. Asimismo, recuerda cómo Sergio acudió primero durante ese duro momento de su vida en el que le tocó enfrentar el fallecimiento de su padre Eric McLuhan en Bogotá horas después de su magnífica conferencia "Media Ecology in the 21st Century". McLuhan y Roncallo son dos nombres/apellidos que quedaron y quedarán siempre unidos en nuestra memoria colectiva y, como lo señala Andrew, serán los guías en este proyecto académico que le da continuidad a la media ecology en América Latina desde el Doctorado en Comunicación.

Debo contar, para cerrar, que el último año y medio fue muy difícil para Sergio. La enfermedad es un monstruo difícil de enfrentar. Pero él lucho contra todo. Incluso logró lo que es más difícil, enfrentarse a sí mismo: la lucha ahora es contra mí, me decía con frecuencia. Por supuesto, tenía el amor y el apoyo de Nadya, su madre; de Juliana, su novia; de Guillermo, de Lucho, de Doly. Ellos estuvieron con él hasta el último instante. Y Sergio batalló como nadie y para mí ganó la guerra contra el tiempo. Una guerra que pocos ganan porque se les va la vida haciendo cosas que no quieren hacer. Ese es el legado de Sergio: hacer siempre lo que él quiso, lo que le dictaba su conciencia, lo que se le daba la gana. Esa es una enseñanza que muchos tenemos que aprender. El tiempo no pudo con él, no lo redujo, no lo venció. Todo lo alcanzó. El hombre más libre que conocí. Y, claro, pen- 
sándolo bien: solo venciendo el tiempo, el tiempo que tenemos y el tiempo que nos queda, es posible permanecer. Estos maravillosos ensayos nos ayudarán, sin duda, a recuperar algo de la seguridad ontológica, ahora nostálgica, que se desvaneció con la pérdida de nuestro maestro: un filósofo, un músico, un escritor, pero, sobre todo, un amigo. Tú permaneces Roncallis.

\section{Referencias}

Barthes, R. (1989). La cámara lúcida. Paidós.

Barthes, R. (2002). Mitologías. Siglo XXI.

Berger, P. (2012). Introducción a la sociología. Limusa.

Elias, N. (1982). Sociología fundamental. Gedisa.

Goffman, E. (2001). La presentación de la persona en la vida cotidiana. Amorrortu.

Heidegger, M. (2006). Ser y tiempo. Trotta.

Logan, R. K. (2010). Understanding new media: Extending Marshall McLuhan. Peter Lang.

Lum, C. (2014). Media ecology: Contexts, concepts, and currents. En R. S. Fortner \& P. M. Fackler (Eds.), The handbook of media and mass communication theory (vol. 1, pp. 137-153). Wiley Blackwell.

Martín-Barbero, J. (1997). De los medios a las mediaciones: comunicación, cultura y hegemonía. Gustavo Gili.

McLuhan, E. (2008). Marshall McLuhan's theory of communication: The yegg. Global Media Journal, 1(1), 25-43. http://gmj-canadianedition.ca//wp-content/uploads/2018/12/inaugural_mcluhan.pdf

Mitchell, W. J. T. (2019). La ciencia de la imagen: Iconología, cultura visual y estética de los medios. Akal. 
Roncallo-Dow, S. (2008). Reconocimiento: entre la posmodernidad inquietante y la búsqueda del agonismo. Universitas Philosophica, 25(50), 95-120. https://revistas.javeriana.edu.co/index.php/vniphilosophica/article/view/11216

Roncallo-Dow, S. (2009a). Marshall McLuhan: la posibilidad de re-leer su noción de medio. Signo y Pensamiento, 28(54), 361-368. https:// revistas.javeriana.edu.co/index.php/signoypensamiento/article/ view/3738

Roncallo-Dow, S. (2009b). Persuasión, seducción y razón: entre la retórica sofística y la dialéctica platónica. Revista Logos, 15, 47-61. https:// www.academia.edu/11248017/Persuasion_Seduction_and_Reason_between_Sophistic_Rhetoric_and_Platonic_Dialectic

Roncallo-Dow, S. (2011). Medios, antimedios, sondas y clichés: revisitando a Marshall McLuhan, el explorador. Signo y Pensamiento, 31(59), 122-138. https://revistas.javeriana.edu.co/index.php/signoypensamiento/article/view/2437

Roncallo-Dow, S., Uribe-Jongbloed, E. y Goyeneche-Gómez, E. (2016). Volver a los clásicos: teorías de la comunicación y cultura pop. Universidad de La Sabana.

Uribe-Jongbloed, E. y Roncallo-Dow, S. (2013). El medio es el mito: entre McLuhan y Barthes. Universitas Philosophica, 30(61), 177-203. https://revistas.javeriana.edu.co/index.php/vniphilosophica/article/view/10642

Watzlawick, P. (2014). No es posible no comunicar. Herder.

Weber, M. (2004). Economía y sociedad. Fondo de Cultura Económica.

Wittgenstein, L. (1999). Investigaciones filosóficas. Altaya. 